\title{
Relationships between heart rate target determined in different exercise testing in COPD patients to prescribed with individualized exercise training
}

This article was published in the following Dove Press journal:

International Journal of COPD

16 May 2017

Number of times this article has been viewed

\author{
Claudine Fabre' \\ Baptiste Chehere' \\ Frédéric Bart ${ }^{2}$ \\ Patrick Mucci' \\ Benoit Wallaert ${ }^{3}$ \\ Jean Marie Grosbois ${ }^{2,4}$ \\ 'University of Lille, EA-7369 - \\ URePSSS, Unité de Recherche \\ Pluridisciplinaire Sport, Santé, Société, \\ Faculté des Sciences du Sport et de \\ I'EP, Ronchin, ${ }^{2}$ Centre Hospitalier \\ Béthune, Service de Pneumologie \\ et d'Allergologie, Rue Delbecque, \\ Beuvry, ${ }^{3}$ CHRU Lille - Service de \\ Pneumologie et Immunoallergologie, \\ Centre des Compétences des \\ Maladies Pulmonaires Rares, Hôpital \\ Calmette, CHRU Lille and Hospital \\ Center Regional University De Lille, \\ Lille, ${ }^{4}$ FormAction Santé, ZA du Bois, \\ Pérenchies, France
}

Correspondence: Claudine Fabre Université de Lille, EA-7369 - URePSSS, Unité de Recherche Pluridisciplinaire Sport, Santé, Société, Faculté des Sciences du Sport et de l'EP, 9 Rue de I'Université, 59790 Ronchin, France

Tel +33 320887376

Fax +33 320887363

Email claudine.fabre@univ-lille2.fr
Background: It has been scientifically proven that pulmonary rehabilitation improves exercise tolerance and facilitates the carrying out of daily physical activities. To optimize the physical and physiological benefits, it is necessary to individualize the training intensity for each patient. The aim of this study is to compare the heart rate (HR) responses to three exercise modalities measuring aerobic fitness in chronic obstructive pulmonary disease patients, in order to easily prescribe individual target HRs for endurance training.

Patients and method: Fifty COPD patients (mean age: $60.1 \pm 8.5$ years) were included in the study. Each patient carried out a cardiopulmonary exercise test, a 6-minute walk test (6MWT) and a 6-minute stepper test (6MST). During these tests, HR was recorded continuously. After the cardiopulmonary exercise test, the HR was noted at the ventilatory threshold (VT) and at the end of the two exercise field tests $\left(6 \mathrm{MWT}_{\text {peak }}\right.$ and $\left.6 \mathrm{MST}_{\text {peak }}\right)$. The values of the HR during the last 3 minutes of both field tests were averaged $\left(6 \mathrm{MWT}_{456}\right.$ and $\left.6 \mathrm{MST}_{456}\right)$. Finally, the HR at $60 \%$ of the HR reserve was calculated with the values of the HR measured during 6MWT and 6MST ( $\left.\mathrm{HRr}_{60 \% \text { walk }}, \mathrm{HRr}_{60 \% \text { step }}\right)$.

Results: The HRs measured during the 6MST were significantly higher than those measured during the $6 \mathrm{MWT}$. The $\mathrm{HRr}_{60 \% \text { step }}$ was not significantly different from $6 \mathrm{MWT}_{456}$ and $6 \mathrm{MWT}_{\text {peak }}$ $\operatorname{HR}(P=0.51 ; P=0.48)$. A significant correlation was observed between $6 \mathrm{MWT}_{456}$ and $6 \mathrm{MWT}_{\text {peak }}$

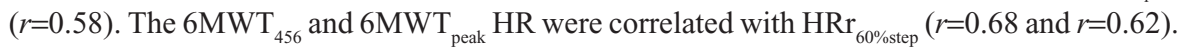
The VT could be determined in 28 patients. The $\mathrm{HR}_{\mathrm{VT}}$ was not different from $6 \mathrm{MWT}_{456}$, $6 \mathrm{MWT}_{\text {peak }}$, and $\mathrm{HRr}_{60 \% \text { step }}(P=0.57, P=0.41$ and $P=0.88)$ and was correlated to $6 \mathrm{MWT}_{456}$, $6 \mathrm{MWT}_{\text {peak }}$, and $\mathrm{HRr}_{60 \% \text { step }}(r=0.45, r=0.40, r=0.48)$.

Conclusion: An individualized target HR for endurance training can be prescribed from the HR measured during routine tests, such as 6MWT or 6MST.

Keywords: cardiopulmonary exercise testing, chronic obstructive pulmonary disease, 6-minute walk test, 6-minute stepper test, endurance training

\section{Introduction}

Exercise training is a major component of pulmonary rehabilitation $(\mathrm{PR})$ allowing an enhancement of the ability to perform activities of daily life and quality of life in patients. An appropriate prescription of exercise during PR is important in ensuring the reduction of dyspnea and asthenia, and peripheral adaptations, especially improvement of muscular function in patients with chronic obstructive pulmonary disease (COPD). ${ }^{1}$ In order to prescribe and individualize physical activities, the patient's exercise capacity needs, therefore, to be assessed. A variety of exercise tests are available for COPD, and chosen according to selected objectives. 
The prescription of endurance exercise is composed of various parameters: frequency, intensity, duration, type (continuous or interval training) and modality (walking, cycling, stepping and so on). Currently, to prescribe and adjust personalized intensity of the exercise during a PR program, cardiopulmonary exercise testing $(\mathrm{CPET})^{2-4}$ is resorted to because of its usefulness in determining the mechanisms of exercise intolerance. Following the CPET, the physiologist use a workload based on a percentage of the peak workload ${ }^{2-6}$ or on a percentage of maximal oxygen uptake observed $\left(\mathrm{VO}_{2 \text { peak }}\right) \cdot{ }^{2,7}$ More conveniently, the heart rate (HR) can be used also to prescribe an intensity, as the $\mathrm{HR}$ at the ventilatory threshold $\left(\mathrm{HR}_{\mathrm{VT}}\right)^{8}$ or a percentage of the peak HR. ${ }^{9}$ The drawback of CPET is the need for trained physiologists to supervise exercise, expensive and specific equipment, and ultimately the $\mathrm{HR}_{\mathrm{VT}}$ may be undetectable. Thus, despite the proven benefits of retraining in COPD patients, it is probable that, in some cases, the inability to perform a CPET is a barrier to the best prescription of exercise intensity.

Field tests are routinely used to evaluate the functional benefits following a PR program in patients with chronic lung disease, ${ }^{10}$ such as the 6 -minute walk test $(6 \mathrm{MWT})^{11-14}$ or the incremental shuttle walking test. ${ }^{15}$ In clinical practice, the 6-minute stepper test (6MST) has been recently proposed as a convenient method to evaluate exercise tolerance because the test can be easily implemented, is inexpensive and feasible to be performed at medical offices or patients' homes. ${ }^{16-19}$ Finally, these tests can be performed in total safety. Despite their usability, field tests are missing in the practical recommendations for prescribing the intensity of retraining during PR. ${ }^{2-4}$ Yet, in patients with chronic heart failure, different field tests are used as alternatives to aerobic exercise prescription..$^{20,21}$ The HR measured at the end of 6MWT $\left(6 \mathrm{MWT}_{\text {peak }}\right)$, which is not different from that of the $\mathrm{HR}_{\mathrm{VT}}$, may be used as reference intensity in patients with chronic heart failure. ${ }^{20,21}$ It would be interesting to find from the HR during the 6MWT and the 6MST a fast marker for medical doctors and patients to prescribe and adjust the intensity of retraining, in different medical offices or in patients' homes.

Previous studies showed that the HR is higher at the end of 6MST (6MST $\mathrm{Meak})$ compared with the 6MWT ${ }_{\text {peak. }}{ }^{22,23}$ This difference could be because of the mobilized muscle mass differences during both tests, resulting in a higher exercise intensity during the 6MST. ${ }^{23}$ We hypothesized that, 1) the $6 \mathrm{MWT}_{\text {peak }}$ and the $\mathrm{HR}_{\mathrm{VT}}$ are not significantly different; and 2) using a percentage of $\mathrm{HR}$ reserve to the 6MST, it is possible to derive an $\mathrm{HR}$ similar to the $\mathrm{HR}_{\mathrm{VT}}$. Thus, the aim of this study is to compare the response of HR during two field tests to the $\mathrm{HR}_{\mathrm{VT}}$ measured during a CPET in order to prescribe easily, at home or in medical offices, an individual intensity of exercise in a COPD population.

\section{Material and methods Subjects}

This monocentric retrospective study included 50 patients with mild-to-severe COPD, managed by outpatient PR. The severity of COPD was evaluated by the Global Initiative for Chronic Obstructive Lung Disease stage (Stage I: mild, FEV / $\mathrm{FVC}<0.70$ and $\mathrm{FEV}_{1} \geq 80 \%$ predicted; Stage II: moderate, $\mathrm{FEV}_{1} / \mathrm{FVC}<0.70$ and $50 \% \leq \mathrm{FEV}_{1}<80 \%$ predicted; Stage III: severe, $\mathrm{FEV}_{1} / \mathrm{FVC}<0.70$ and $30 \% \leq \mathrm{FEV}_{1}<50 \%$ predicted; Stage IV: very severe, $\mathrm{FEV}_{1} / \mathrm{FVC}<0.70$ and $\mathrm{FEV}_{1}<30 \%$ predicted or $\mathrm{FEV}_{1}<50 \%$ predicted plus chronic respiratory failure).${ }^{24}$ All patients included in this study had pre-rehabilitation 6MWT, 6MST, and CPET assessment data available. The study protocol was approved by the Observational Research Protocol Evaluation Committee of the French Language Society of Pulmonology, France (CEPRO $n^{\circ}$ 2011-036). All the participants provided written informed consent to take part in this study. Inclusion criteria were: stable disease without exacerbation for at least 4 weeks, and no muscular, cardiovascular or neurological problems that limited the performance of a physical exercise. Patients on oxygen therapy were not included in the study. The characteristics of the patients are presented in Table 1.

Table I Characteristics of 50 patients with COPD

\begin{tabular}{|c|c|}
\hline Variable (unit) & Mean \pm SD \\
\hline $\operatorname{Sex}(F / M)$ & $7 / 43$ \\
\hline Age (years) & $60.1 \pm 8.5$ \\
\hline $\mathrm{BMl}^{\mathrm{a}}\left(\mathrm{kg} / \mathrm{m}^{2}\right)$ & $27.0 \pm 5.8$ \\
\hline \multicolumn{2}{|l|}{ Spirometry } \\
\hline $\mathrm{FEV}_{1}{ }^{\mathrm{b}}(\mathrm{L})$ & $1.8 \pm 0.6$ \\
\hline $\mathrm{FEV}, \% *$ & $56.9 \pm 19.6$ \\
\hline $\mathrm{FVC}^{\mathrm{c}}(\mathrm{L})$ & $3.1 \pm 0.9$ \\
\hline FVC (\%)* & $75.8 \pm 25.1$ \\
\hline $\mathrm{FEV}_{\mathrm{l}} / \mathrm{FVC}(\%)$ & $58 \pm 12$ \\
\hline \multicolumn{2}{|l|}{ Data at exercise } \\
\hline $\mathrm{VO}_{2}{ }^{d}$ peak (mL/kg/minute) & $15.2 \pm 4.6$ \\
\hline $\mathrm{VO}_{2 \max }$ predicted (\%) & $59.6 \pm 35.2$ \\
\hline Maximal power (watts) & $94.5 \pm 33.1$ \\
\hline 6-minute walk test $(\mathrm{m})$ & $4 I I \pm 7 \mid$ \\
\hline 6-minute stepper test (strokes) & $526 \pm 125$ \\
\hline
\end{tabular}

Notes: *Expressed values in percentage of predicted values. aBody mass index; bForced expiratory lung volume during the first second; 'Forced vital capacity; ¿Oxygen consumption.

Abbreviations: BMI, body mass index; COPD, chronic obstructive pulmonary disease; $\mathrm{FEV}_{1}$, forced expiratory lung volume during the first second; FVC, forced vital capacity; $F$, female; $M$, male; $S D$, standard deviation; $\mathrm{VO}_{2 \text { max }}$ expressed values in percentage of predicted values. 


\section{Protocol}

Each patient completed a spirometry (Ergocard, Medisoft, Sorinnes, Belgium) followed by three assessments of aerobic fitness: a CPET on a cycle ergometer (Ergometrics 800, Ergoline, Bitz, Germany), a 6MWT and a 6MST. For safety reasons, the CPET was carried out first, to detect any cardiovascular abnormalities, thus removing contraindications to the exercise. Two to five days later, patients performed a 6MWT and 6MST, always in this order. A rest period between the two tests was established for at least 30 minutes to enable the return of the heart rate to the resting value.

\section{Cardiopulmonary exercise testing}

CPET was performed according to an incremental protocol on a cycle ergometer (Ergometrics 800), with blood pressure and electrocardiographic monitoring (Medcard ${ }^{\circledR}$; Medisoft, Dinant, Belgium), according to the usual guidelines. ${ }^{25}$ The protocol included a 3-minute rest period, a 3-minute unloaded pedaling period, an incremental ramp exercise $(10-15 \mathrm{~W} / \mathrm{min})$ pursued to a symptom-limited end point, and a 3-minute recovery time. Inspired and expired gases were collected by a mouthpiece connected to a gas analyzer. Gas exchange was measured breath-by-breath by a computerized system (Ergocard, Medisoft). The exercise was stopped when the subjects, in spite of verbal encouragement, were unable to maintain the imposed pedaling rhythm of 55-60 revolutions per minute. All CPET were limited by dyspnea, fatigue, or both. The oxygen saturation $\left(\mathrm{SpO}_{2}\right)$ was measured using a portable oximeter (Nonin Oxymontre 3100; Nonin, Plymouth, MN, USA).

\section{Determination of the HR at the ventilatory threshold (VT)}

At the end of the CPET, VT was determined by two blinded and independent investigators; VT was defined by an increase in the respiratory equivalent for oxygen with no increase in the respiratory equivalent for carbon dioxide. ${ }^{26}$ The $\mathrm{HR}_{\mathrm{VT}}$ was recorded.

\section{Field tests}

The six-minute walk test

The 6MWT was performed over a rectangular distance of 70 $m$ in the respiratory medicine department. With the exception of this point, the American Thoracic Society guidelines for 6MWT were followed. ${ }^{27}$

\section{The six-minute stepper test}

The stepper (Go Sport, Grenoble, France) was placed on the ground facing a wall to allow patients to maintain their balance by placing their fingers on the wall. ${ }^{18,28}$ The step height was set at $20 \mathrm{~cm}$. Patients received standardized instructions adapted from the 6MWT instructions, ${ }^{29}$ advising them to make the greatest number of steps they could in 6 minutes.

For the two field tests, the protocol included a 3-minute rest period and a 6-minute walking or stepping period. During these periods, continuous monitoring of $\mathrm{HR}$ and $\mathrm{SpO}_{2}$ were recorded by a pulse oximeter (Nonin Oxymontre 3100).

No encouragement during these two tests was given; the only indication provided was the remaining time, every minute. The values of the HR of both tests during the last 3 minutes of exercise were averaged $\left(6 \mathrm{MWT}_{456}\right.$ and $\left.6 \mathrm{MST}_{456}\right)$. The peak $\mathrm{HR}$ at the end of exercise was noted $\left(6 \mathrm{MWT}_{\text {peak }}\right.$ and $\left.6 \mathrm{MST}_{\text {peak }}\right)$.

\section{Calculation of the target HR at $60 \%$ of the heart rate reserve $(\mathrm{HRr})$}

The HRr was calculated as the HR at the sixth minute $\left(\mathrm{HR}_{\text {peak }}\right)-$ resting $\mathrm{HR}\left(\mathrm{HR}_{\mathrm{res}}\right)$. According to the formula of Karvonen et al, ${ }^{30} 60 \%$ of $\mathrm{HRr}$ corresponds to the following equation: $\mathrm{HRr}_{60 \%}=\left(\mathrm{HR}_{\text {peak }}-\mathrm{HR}_{\text {rest }}\right) * 0.6+\mathrm{HR}_{\text {rest }}$. $\mathrm{HR}_{\text {rest }}$ was measured in a sitting position; $\mathrm{HR}_{\text {peak }}$ was the maximum $\mathrm{HR}$ measured at the end of the 6MWT and 6MST (6MWT $\left.\mathrm{Meak}_{\text {and }} 6 \mathrm{MST}_{\text {peak }}\right)$.

\section{Statistical analysis}

Data are reported by means $\pm 95 \%$ confidence intervals (CIs). The normal distribution of the data was verified by the Kolmogorov-Smirnov test before the interpretation of the analysis of variance (ANOVA). To compare the evolution of HR at rest and at each minute of 6MWT and 6MST, we used an ANOVA on rank for repeated measures (time and test). When the ANOVA test was significant at $P<0.05$, Tukey's post hoc test for multiple comparisons was applied. To compare the following variables with each other: $6 \mathrm{MWT}_{\text {peak }}, 6 \mathrm{MST}_{\text {peak }}$, $6 \mathrm{MWT}_{456}, 6 \mathrm{MST}_{456}, \mathrm{HR}_{\mathrm{VT}}, \mathrm{HRr}_{60 \% \text { walk }}$, and $\mathrm{HRr}_{60 \% \text { step }}$, a one-way ANOVA for repeated measures was applied.

Pearson's correlation coefficient was used to evaluate correlations between the different heart rates of the various exercise tests performed by the patients (CPET, 6MWT, and 6MST). A linear regression was performed to analyze the independent correlations between the HR averages during the last 3 minutes of each test and the HR calculated at $60 \% \mathrm{HRr}$. A correlation $>0.90$ was considered very high; between 0.70 and 0.89 as high; and between 0.50 and 0.69 as moderate. ${ }^{31}$ The significance level was set at 5\%.

\section{Results}

The characteristics of the 50 COPD patients included in this study are presented in Table 1. The responses of the HR to 
Table 2 Heart rate measured in the two field exercise tests in 50 COPD patients

\begin{tabular}{ll}
\hline Tests (unit) & Mean $(95 \% \mathrm{Cl})$ \\
\hline $6 \mathrm{MWT}^{\mathrm{a}}$ (beat.minute $\left.{ }^{-1}\right)$ & \\
$6 \mathrm{MWT}_{456}^{\mathrm{b}}$ & $106(86-126)$ \\
$6 \mathrm{MWT}_{\text {peak }}^{\mathrm{c}}$ & $106(85-127)$ \\
$\mathrm{HRr}_{60 \% \text { walk }}{ }^{\mathrm{d}}$ & $99(78-120)$ \\
$6 \mathrm{MST}^{\mathrm{e}}$ (beat.minute $\left.{ }^{-1}\right)$ & \\
$6 \mathrm{MST}_{456}^{\mathrm{f}}$ & $116(84-149)$ \\
$6 \mathrm{MST}_{\text {peak }}^{\mathrm{g}}{ }_{\mathrm{h}}^{\mathrm{g}}$ & $118(83-152)$ \\
$\mathrm{HRr}_{60 \% \text { step }}$ & $108(77-139)$ \\
\hline
\end{tabular}

Notes: Results are expressed as means, and $95 \% \mathrm{Cl}$. ${ }^{\mathrm{a}} 6 \mathrm{MWT}$; ${ }^{\mathrm{b}}$ Averaged heart rate measured during the last 3 minutes of $6 \mathrm{MWT}$; 'Peak heart rate measured at the end of $6 \mathrm{MWT} ;{ }^{\mathrm{d}}\left(6 \mathrm{MWT} \mathrm{T}_{\text {peak }}-\mathrm{HR}_{\text {rest }}\right) \times 0.6+\mathrm{HR}_{\text {rest }}$; ${ }^{\mathrm{e}} \mathrm{MMST}$; ${ }^{\mathrm{f}}$ Averaged heart rate measured

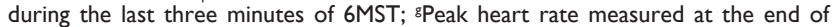
6MST; ${ }^{\mathrm{h}}\left(6 \mathrm{MST}_{\text {peak }}-\mathrm{HR}_{\text {rest }}\right) \times 0.6+\mathrm{HR}_{\text {rest }}$.

Abbreviations: $\mathrm{Cl}$, confidence interval; COPD, chronic obstructive pulmonary disease; HR, heart rate; 6MST, 6-minute stepper test; 6MWT, 6-minute walk test.

the different evaluation tests are reported in Table 2. The HRs measured during the 6MST were significantly higher than those measured during the 6MWT (Figure 1). However, the $\mathrm{HRr}_{60 \% \text { step }}$ was not significantly different from $6 \mathrm{MWT}_{456}$ and $6 \mathrm{MWT}_{\text {peak }}(P=0.51 ; P=0.48$, respectively). In the same way, $6 \mathrm{MWT}_{456}$ and $6 \mathrm{MWT}_{\text {peak }}$ were significantly correlated with $\mathrm{HRr}_{60 \% \text { step }}(r=0.68, P<0.001 ; r=0.62, P<0.001$, respectively, Figure 2). The $\mathrm{HRr}_{60 \% \text { walk }}$ was significantly different from $6 \mathrm{MWT}_{\text {peak }}, 6 \mathrm{MWT}_{456}, 6 \mathrm{MST}_{456}$, and $6 \mathrm{MST}_{\text {peak }}(P=0.001)$.

Among the 50 patients, the VT could be determined in only 28 COPD patients. The $\mathrm{HR}_{\mathrm{VT}}$ (106 beat.minute ${ }^{-1}$, CI 95\% 80-134) was not significantly different from $6 \mathrm{MWT}_{456}, 6 \mathrm{MWT}_{\text {peak }}$, and $\operatorname{HRr}_{60 \% \text { step }}(P=0.57, P=0.41$,

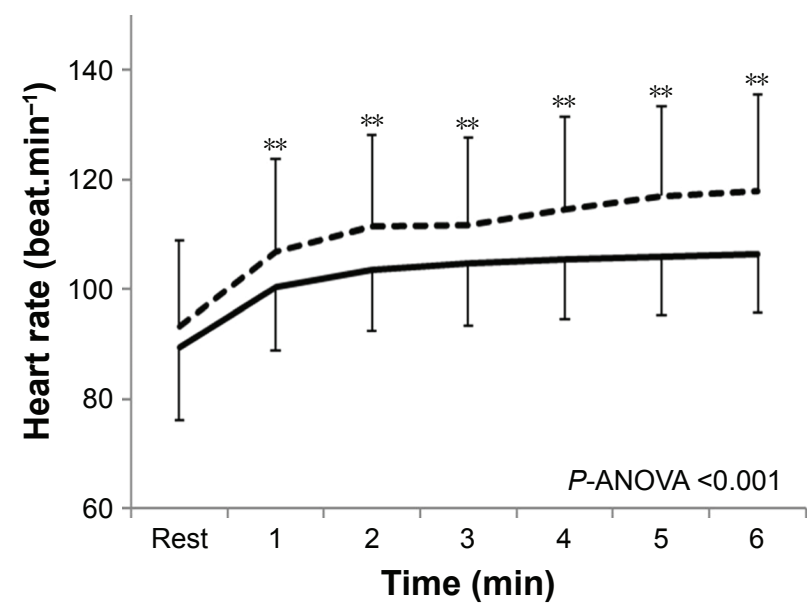

Figure I Patterns of response in the heart rate during the 6MWT and 6MST in 50 COPD patients.

Notes: Solid line, 6MWT; dotted line, 6MST. $* * P<0.00$ I for inter-test differences determined by ANOVA followed by Tukey's post hoc test for multiple comparisons. Abbreviations: ANOVA, analysis of variance; 6MST, 6-minute stepper test; 6MWT, 6-minute walk test. and $P=0.88$, respectively) but significantly different from $\mathrm{HRr}_{60 \% \text { walk }}(P=0.001)$. In these $28 \mathrm{COPD}$ patients, the $\mathrm{HR}_{\mathrm{VT}}$ was significantly correlated to $6 \mathrm{MWT}_{456}, 6 \mathrm{MWT}_{\text {peak }}$, and $\mathrm{HRr}_{60 \% \text { step }}(r=0.45, P=0.02 ; r=0.40, P=0.03 ; r=0.48, P=0.02$, respectively, Figure 3 ).

\section{Discussion}

The aim of our study was to compare the responses of HR during three exercise tests (6MWT, 6MST and CPET) and to compare these responses in order to prescribe an easily individualized target HR for endurance training. The main result of this study is that, from a field test of 6 minutes (6MWT or $6 \mathrm{MST})$, it is possible to use heart rate, $6 \mathrm{MWT}_{456}$ and $6 \mathrm{MWT}_{\text {peak }}$, or $\mathrm{HRr}_{60 \% \text { step, }}$ as a simple marker for the prescription of exercise intensity for an individualized endurance training in patients with COPD.

The review of Achten and Jeukendrup ${ }^{32}$ has demonstrated the utility of using HR to individualize, at best, training intensity. HR is easily programmable, and COPD patients can use it immediately to adjust the workout intensity during complex exercises, such as interval training or walking outdoors on uneven terrain, with a HR monitor or other connected objects. Finally, data regarding the HR can be downloaded, which makes possible the analysis of training sessions in the absence of a professional on site.

Interest in using $\mathrm{HR}_{\mathrm{vT}}$ as a training intensity marker has been demonstrated in the associated literature with cardiorespiratory and metabolic adaptations and exercise tolerance following an aerobic training program. ${ }^{8,33,34}$ So, our results show no significant differences between the $\mathrm{HR}_{\mathrm{VT}}$, the $6 \mathrm{MWT}_{456}$, and the $6 \mathrm{MWT}_{\text {peak }}$. Our results demonstrate that the $6 \mathrm{MWT}_{456}$ and $6 \mathrm{MWT}_{\text {peak }}$ can be prescribed as a target for personalized exercise intensity as demonstrated in previous studies in patients with heart failure. ${ }^{20,21}$ However, as previously mentioned, the walking test requires a corridor at least $30 \mathrm{~m}$ long, which may be limiting under certain conditions in medical offices and at home. Looking at the measured HRs on a stepper, our results showed a correlation between the $\mathrm{HR}_{\mathrm{VT}}$ and the $\mathrm{HRr}_{60 \% \text { step }}$, indicating that the 6MST can be used to prescribe individualized exercise intensity. This result is interesting because of the fact that the major limitation to prescribe an individualized intensity at home or medical offices can be avoided. We expected a difference in measured HRs between stepper and walking tests because, in the literature, $\mathrm{HR}_{\text {peak }}$ is always higher for the stepper than for the walking test. ${ }^{22,23}$ This difference could be because of the mobilized muscle mass differences during both tests resulting in a higher exercise intensity during the $6 \mathrm{MST}^{23}$ 
A

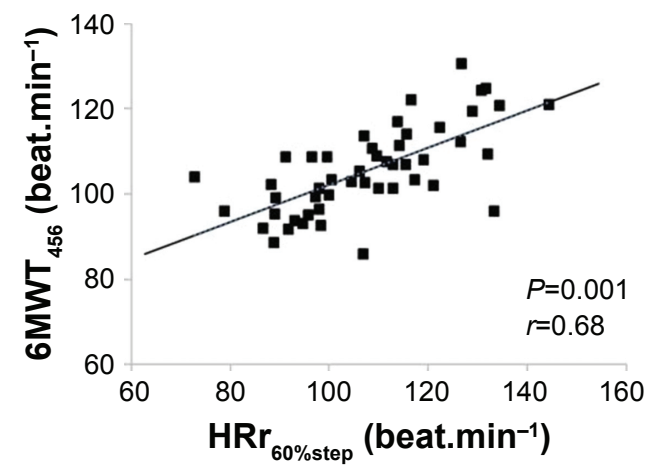

B

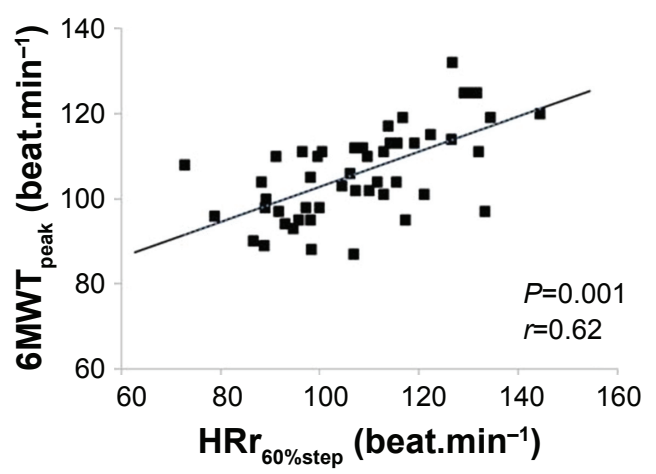

Figure 2 Correlations between heart rates noted at $\mathrm{HRr}_{60 \% \text { step }}$ and $6 \mathrm{MWT}_{456}(\mathbf{A})$, and 6MWT

Notes: $6 \mathrm{MWT}_{456}$, averaged heart rate measured during the last 3 minutes of the $6 \mathrm{MWT}$; $6 \mathrm{MWT}$ peak , peak heart rate measured at the end of the $6 \mathrm{MWT}$; HRr ${ }_{60 \% \text { step' }}$ $\left(6 \mathrm{MST}_{\text {peak }}-6 \mathrm{MST}_{\text {rest }}\right) \times 0.6+6 \mathrm{MST}_{\text {rest: }}$.

Abbreviations: HR, heart rate; 6MST, 6-minute stepper test; 6MWT, 6-minute walk test.

In the literature, there are numerous methods described that determine target HRs for endurance training. The intensity of exercise training can be defined by metabolic equivalent of task (METS), calculated as a percentage of $\mathrm{VO}_{2 \max }$, a percentage of $\mathrm{VO}_{2}$ reserve, or even as a percentage of the theoretical maximum HR. ${ }^{35}$ The choice, in our study, to focus exclusively on the HR arises from the observation that this variable is easily specified by the clinician, understandable and observable for the patient, easy to measure (by HR sensor or pulse taken at the wrist), can be used in a variety of environments and during many forms of exercise (biking, walking, gardening), and easy and cheap to use when
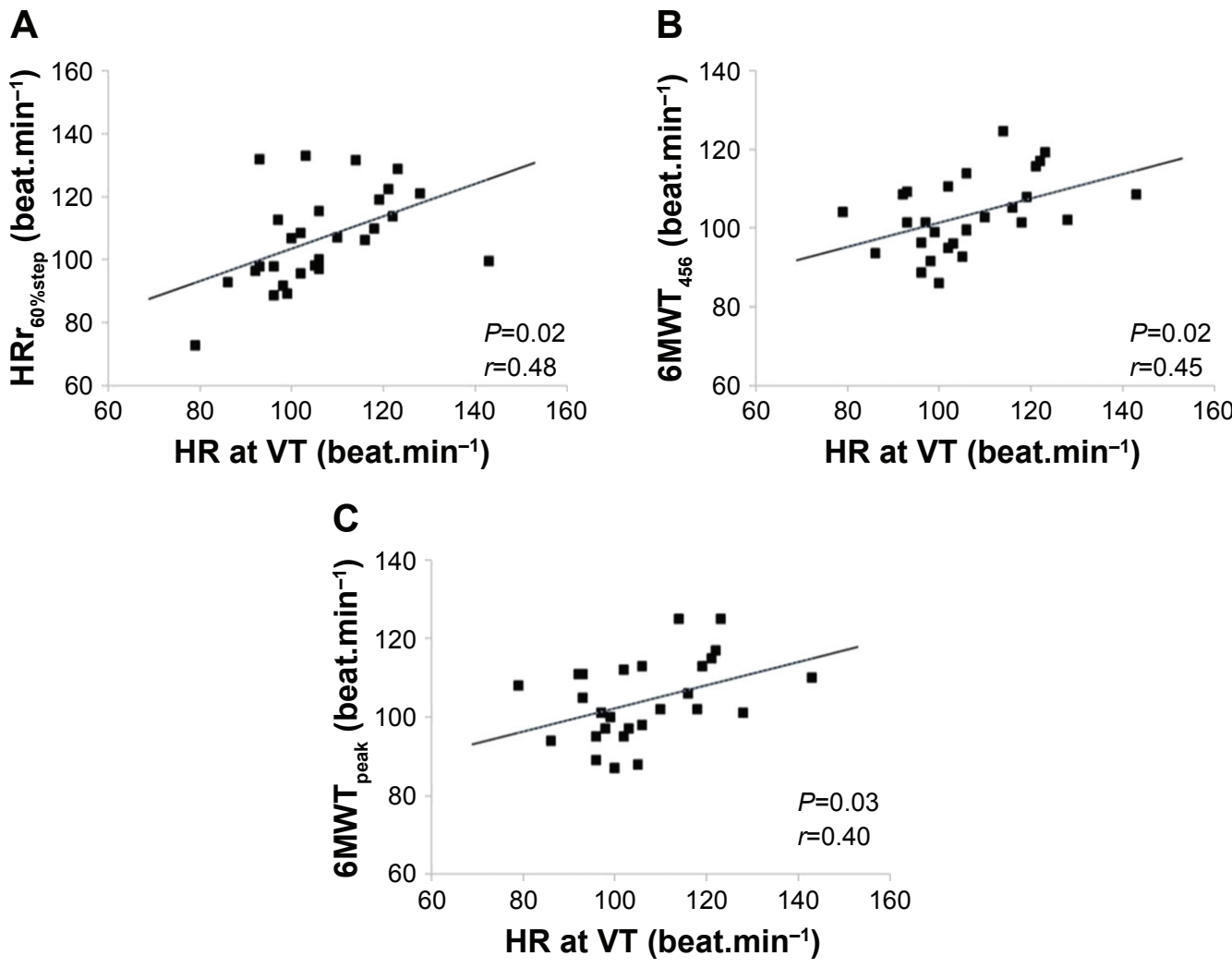

Figure 3 Correlations between HR noted at VT and (A) $\mathrm{HRr}_{60 \% \text { step }}$ (B) $6 \mathrm{MWT}_{456}$, and (C) $6 \mathrm{MWT}$ peak in 28 COPD patients.

Notes: HR at VT, HR noted at the ventilatory threshold; $6 \mathrm{MWT}_{456}$, averaged heart rate measured during the last 3 minutes of the $6 \mathrm{MWT} ; 6 \mathrm{MWT}$ peak ${ }^{400 a r t}$ rate measured at the end of the 6MWT; $\mathrm{HRr}_{60 \% \text { step}},\left(6 \mathrm{MST}_{\text {peak }}-6 \mathrm{MST}_{\text {rest }}\right) * 0.6+6 \mathrm{MST}_{\text {rest }}$

Abbreviations: HR, heart rate; $6 \mathrm{MST}$, 6-minute stepper test; $6 \mathrm{MWT}$, 6-minute walk test; VT, ventilatory threshold. 
the patient is alone at the exit of the PR program. Thereby, Simmons et $\mathrm{al}^{36}$ demonstrated the utility of using the HR as a marker for the intensity of the exercise.

Some methodological limitations of this study must be presented. The HR measurement is influenced by many factors. First, in our study, the HR was measured in laboratory conditions where the environment was controlled. However, away from this controlled environment, many factors such as wind, cold, or heat can influence the rhythm of the HRs. Second, there is a HR variability between the morning and the afternoon. ${ }^{37}$ Finally, after several minutes of exercise' of mild-to-moderate intensity, there is a gradual decrease in stroke volume associated with an increase in HR; this instability is termed cardiac drift. Rowell ${ }^{38}$ hypothesized that this drift is related to the combination of water loss and peripheral vasodilation induced by exercise. Thus, a $15 \%$ increase in HR during exercise can be noted. Keeping in mind these alterations, it is possible to give patients not a target HR, but rather a range bracket of HR during training. Most HR sensors are able to program training intensity to match the target HR \pm 5 beats per minute. This technique is proposed in daily practice to our COPD patients.

In conclusion, our results demonstrate that exercise training intensity can be individually prescribed from the HR measured during routine tests such as the 6MWT or $6 \mathrm{MST}$. If the spatial conditions allow, the $6 \mathrm{MWT}_{456}$ and $6 \mathrm{MWT}_{\text {peak }}$ can be used as a target HR for the prescription of the intensity of exercise. When space is restricted, the 6MST can be used to prescribe the exercise training intensity using the $\mathrm{HRr}_{60 \% \text { step }}$.

\section{Author contributions}

$\mathrm{CF}, \mathrm{BC}, \mathrm{FB}, \mathrm{BW}$, and JMG substantially contributed to conception and design, acquisition of data, or analysis and interpretation of data. $\mathrm{CF}, \mathrm{BC}, \mathrm{FB}, \mathrm{PM}$, and $\mathrm{BW}$ drafted the article or revised it critically for important intellectual content. CF, BC, FB, PM, BW and JMG made the final approval of the version to be published. CF, BC, FB, PM, $\mathrm{BW}$ and $\mathrm{JMG}$, agreed all aspects of the work in ensuring that questions related to the accuracy or integrity of any part of the work were appropriately investigated and resolved. All authors contributed toward data analysis, drafting and critically revising the paper and agreed to be accountable for all aspects of the work.

\section{Disclosure}

The authors report no conflicts of interest in this work.

\section{References}

1. McCarthy B, Casey D, Devane D, Murphy K, Murphy E, Lacasse Y. Pulmonary rehabilitation for chronic obstructive pulmonary disease. Cochrane Database Syst Rev. 2015;(2):CD003793.

2. Zainuldin R, Mackey MG, Alison JA. Optimal intensity and type of leg exercise training for people with chronic obstructive pulmonary disease. Cochrane Database Syst Rev. 2011;(11):CD008008.

3. Nici L, Donner C, Wouters E, et al. American Thoracic Society/ European Respiratory Society Statement on pulmonary rehabilitation. Am J Respir Crit Care Med. 2006;173(12):1390-1413.

4. Gloeckl R, Marinov B, Pitta F. Practical recommendations for exercise training in patients with COPD. Eur Respir Rev. 2013;22(128): 178-186.

5. Troosters T, Casaburi R, Gosselink R, Decramer M. Pulmonary rehabilitation in chronic obstructive pulmonary disease. Am J Respir Crit Care Med. 2005;172(1):19-38.

6. Spruit MA, Singh SJ, Garvey C, et al. An official American Thoracic Society/European Respiratory Society Statement: key concepts and advances in pulmonary rehabilitation. Am J Respir Crit Care Med. 2013;188(8):e13-e64.

7. Cooper CB. Exercise in chronic pulmonary disease: aerobic exercise prescription. Med Sci Sports Exerc. 2001;33(7 Suppl):S671-S679.

8. Vallet G, Ahmaïdi S, Serres I, et al. Comparison of two training programmes in chronic airway limitation patients: standardized versus individualized protocols. Eur Respir J. 1997;10(1):114-122.

9. Breyer MK, Breyer-Kohansal R, Funk GC, et al. Nordic walking improves daily physical activities in COPD: a randomised controlled trial. Respir Res. 2010;11:112.

10. Mador MJ, Modi K. Comparing various exercise tests for assessing the response to pulmonary rehabilitation in patients with COPD. J Cardiopulm Rehabil Prev. 2016;36(2):132-139.

11. Redelmeier DA, Bayoumi AM, Goldstein RS, Guyatt GH. Interpreting small differences in functional status: the six minute walk test in chronic lung disease patients. Am J Respir Crit Care Med. 1997;155(4): 1278-1282.

12. Puhan MA, Mador MJ, Held U, Goldstein R, Guyatt GH, Schünemann HJ. Interpretation of treatment changes in 6-minute walk distance in patients with COPD. Eur Respir J. 2008;32(3):637-643.

13. Holland AE, Hill CJ, Rasekaba T, Lee A, Naughton MT, McDonald CF. Updating the minimal important difference for six-minute walk distance in patients with chronic obstructive pulmonary disease. Arch Phys Med Rehabil. 2010;91(2):221-225.

14. Puhan MA, Chandra D, Mosenifar Z, et al; National Emphysema Treatment Trial (NETT) Research Group. The minimal important difference of exercise tests in severe COPD. Eur Respir J. 2011;37(4): 784-790.

15. Singh SJ, Morgan MD, Hardman AE, Rowe C, Bardsley PA. Comparison of oxygen uptake during a conventional treadmill test and the shuttle walking test in chronic airflow limitation. Eur Respir J. 1994;7: 2016-2020.

16. Rammaert B, Leroy S, Cavestri B, Wallaert B, Grosbois JM. Homebased pulmonary rehabilitation in idiopathic pulmonary fibrosis. Rev Mal Respir. 2011;28(7):e52-e57.

17. Grosbois JM, Gicquello A, Langlois C, et al. Long-term evaluation of home-based pulmonary rehabilitation in patients with COPD. Int $J$ Chron Obstruct Pulmon Dis. 2015;10:2037-2044.

18. Grosbois JM, Riquier C, Chehere B, et al. Six-minute stepper test: a valid clinical exercise tolerance test for COPD patients. Int $J$ Chron Obstruct Pulmon Dis. 2016;11:657-663.

19. Pichon R, Couturaud F, Mialon P, et al. Responsiveness and minimally important difference of the 6-minute stepper test in patients with chronic obstructive pulmonary disease. Respiration. 2016;91(5): 367-373.

20. Oliveira MF, Zanussi G, Sprovieri B, et al. Alternatives to aerobic exercise prescription in patients with chronic heart failure. Arq Bras Cardiol. 2016;106(2):97-104. 
21. Gremeaux M, Hannequin A, Laurent Y, Laroche D, Casillas JM, Gremeaux V. Usefulness of the 6-minute walk test and the 200-metre fast walk test to individualize high intensity interval and continuous exercise training in coronary artery disease patients after acute coronary syndrome: a pilot controlled clinical study. Clin Rehabil. 2011;25(9):844-855.

22. Delourme J, Stervinou-Wemeau L, Salleron J, Grosbois JM, Wallaert B. Six-minute stepper test to assess effort intolerance in interstitial lung diseases. Sarcoidosis Vasc Diffuse Lung Dis. 2012;29(2):107-112.

23. Chéhère B, Bougault V, Gicquello A, Wallaert B. Cardiorespiratory response to different exercise tests in interstitial lung disease. Med Sci Sports Exerc. 2016;48(12):2345-2352.

24. Rabe KF, Hurd S, Anzueto A, et al. Global strategy for the diagnosis, management, and prevention of chronic obstructive pulmonary disease: GOLD executive summary. Am J Respir Crit Care Med. 2007;176(6): 532-555.

25. American Thoracic Society, American College of Chest Physicians. ATS/ACCP Statement on cardiopulmonary exercise testing. Am J Respir Crit Care Med. 2003;167(2):211-277.

26. Wasserman K, Whipp BJ, Koyl SN, Beaver WL. Anaerobic threshold and respiratory gas exchange during exercise. J Appl Physiol. 1973; 35(2):236-243.

27. ATS Committee on Proficiency Standards for Clinical Pulmonary Function Laboratories. ATS statement: guidelines for the six-minute walk test. Am J Respir Crit Care Med. 2002;166(1):111-117.

28. Coquart JB, Lemaître F, Castres I, Saison S, Bart F, Grosbois JM. Reproducibility and sensitivity of the 6-minute stepper test in patients with COPD. COPD. 2015;12(5):533-538.
29. Borel B, Fabre C, Saison S, Bart F, Grosbois JM. An original field evaluation test for chronic obstructive pulmonary disease population: the six-minute stepper test. Clin Rehabil. 2010;24(1):82-93.

30. Karvonen MJ, Kentala E, Mustala O. The effects of training on heart rate; a longitudinal study. Ann Med Exp Biol Fenn. 1957;35(3):307-315.

31. Munro BH. Statistical Methods for Health Care Research. New York: Lippincott Williams \& Wilkins; 2005.

32. Achten J, Jeukendrup AE. Heart rate monitoring: applications and limitations. Sports Med Auckl NZ. 2003;33(7):517-538.

33. Alfaro V, Torras R, Prats MT, Palacios L, Ibáñez J. Improvement in exercise tolerance and spirometric values in stable chronic obstructive pulmonary disease patients after an individualized outpatient rehabilitation programme. J Sports Med Phys Fitness. 1996;36(3):195-203.

34. Serres I, Varray A, Vallet G, Micallef JP, Préfaut C. Improved skeletal muscle performance after individualized exercise training in patients with chronic obstructive pulmonary disease. J Cardiopulm Rehabil. 1997; 17(4):232-238.

35. American Thoracic Society. Pulmonary rehabilitation-1999. American Thoracic Society. Am J Respir Crit Care Med. 1999;159(5 Pt 1): 1666-1682.

36. Simmons DN, Berry MJ, Hayes SI, Walschlager SA. The relationship between $\% \mathrm{HRpeak}$ and $\% \mathrm{VO}_{2}$ peak in patients with chronic obstructive pulmonary disease. Med Sci Sports Exerc. 2000;32(5):881-886.

37. Kervio G, Carre F, Ville NS. Reliability and intensity of the six-minute walk test in healthy elderly subjects. Med Sci Sports Exerc. 2003;35(1): $169-174$.

38. Rowell LB. Human cardiovascular adjustments to exercise and thermal stress. Physiol Rev. 1974;54(1):75-159.
International Journal of COPD

\section{Publish your work in this journal}

The International Journal of COPD is an international, peer-reviewed journal of therapeutics and pharmacology focusing on concise rapid reporting of clinical studies and reviews in COPD. Special focus is given to the pathophysiological processes underlying the disease, intervention programs, patient focused education, and self management protocols.

\section{Dovepress}

This journal is indexed on PubMed Central, MedLine and CAS. The manuscript management system is completely online and includes a very quick and fair peer-review system, which is all easy to use. Visit http://www.dovepress.com/testimonials.php to read real quotes from published authors. 